\title{
The Analysis of Earth Pressure on Retaining Wall based on ABAQUS
}

\author{
Jie $A i^{1, a}$, Jin song Gui ${ }^{1, b}$ Ding Chen ${ }^{1, c}$ \\ ${ }^{1}$ School of Marine and Civil Engineering, Dalian Ocean University, Dalian, Liaoning 116023, China \\ a814648486@qq.com, bguijs@163.com, c346970644@qq.com
}

Keywords: Rigid wall; Flexible wall; ABAQUS; Earth pressure;

Abstract. In order to study the distribution of earth pressure on retaining wall, the universal software- ABAQUS is used in this passage to have established a finite element numerical calculation model for the structure of retaining wall. It calculates both the earth pressure on the structure of retaining wall from different sections under the same conditions and under different geological conditions. After analyzing and studying the results, we get the conclusion that the earth pressure on rigid wall and flexible wall presents " $\mathrm{R}$ " type distribution, which is consistent with the classical theory. And ABAQUS is well adapted for researching on geotechnical problems.

\section{Introduction}

Retaining wall is widely used in building construction, water conservancy, railways, highways, harbor and other projects. A retaining wall is a structure designed and constructed to resist the lateral pressure of soil, restraining soil to unnatural collapse and slopes. A retaining wall can be classified as rigid wall and flexible wall by their deformation and destruction forms. The integral deformation of a rigid wall is called shear deformation, a sort of shear wreck,or brittle wreck, also called rigid wreck; While the integral deformation of flexible wall mostly presents bending deformation, a type of bending wreck, so it is called flexible wall. Generally speaking, rigid retaining wall is gravity retaining wall,and flexible retaining wall is sheet pile retaining wall.

The main external-load on retaining wall is from earth pressure., which can be set as three catagories: the active earth pressure, static earth pressure and passive earth pressure. Usually the active earth pressure and static earth pressure are the main pressures on the gravity retaining wall ${ }^{[1]}$.

The finite element analysis software ABAQUS developed and maintained by Sauder SIMULIA company has been widely accepted by global industry and academia. ABAQUS is well-equipped with the constitutive model reflecting the character of soil authentically, being able to perform the calculation of effective stress. It evolves powerful interface-processing functions to simulate the release between soil and structure, the phenomenon such as slip, and the ability of handling the specific problems in geotechnical engineering process such as filling and excavation., Moreover, it can set up the initial stress state flexibly, and it has a strong applicability to calculate the retaining wall structure ${ }^{[2][3]}$.

\section{The simplified model}

According to the symmetry of load and the structure, we can take $5 \mathrm{~m}$ thick retaining wall in the direction perpendicular to the axisand the soila certain range before and after the retaining wallto establish finite element model .To analyze the soil pressure, we can take foundation area of width 5 timesmore than wall's width from two sides of the wall, to eliminate the influence of boundary constraints on both ends. We can take soil layer of thickness 1.0-1.5 times thicker than that of height of the wall in Vertical direction, to eliminate the influence of the bottom boundary constraints.

When making model, the rigid retaining wall model will be $10 \mathrm{~m} \times 7 \mathrm{~m} \times 5 \mathrm{~m}$ (height $\times$ width $\times$ thickness).Flexible retaining wall model will be $20 \mathrm{~m} \times 5 \mathrm{~m} \times 0.4 \mathrm{~m}$ (height $\times$ width $\times$ thickness), $10 \mathrm{~m}$ deep in soil.Soil model size will be $40 \mathrm{~m}$ x $40 \mathrm{~m}$ x $5 \mathrm{~m}$ (height $\times$ width $\times$ thickness) in shorter side; $50 \mathrm{~m} \times 60 \mathrm{~m} \times 5 \mathrm{~m}$ (height $\times$ width $\times$ thickness) in high side. More information and data please refer to table 1 . 
The boundary before and after the model is the symmetry constraint around $\mathrm{Z}$ plane ,the left and right boundary is the pole constraints in the vertical chain of $\mathrm{X}$ plane ,the bottom is clamped constraints.X direction chain Pole constraints is imposed on the part of flexible retaining wall which is $1 \mathrm{~m}$ distance from the top of wall .Soil structure and the mutual coupling, non-linear problem belongs to the boundary conditions, by defining contact to simulate the contact.Consideringthe relative sliding, separation and periodic off and on of the contact surfaces, according to the laws of the sliding, we can use small sliding between point and surface tosimulate the relative sliding. Contact surface tangential role will be defined by a friction formula. The average friction coefficient is 0.3 . The Normal function use "hard" formula that only passing pressure don't pull. Retaining wall and soil adopts linear reduced integral unit 8 node hexahedron C3D8R, and select the type of Hex mesh. According to the edge of cloth kind retaining wall grid size is $0.9 \mathrm{~m}$, the soil grid size is $2 \mathrm{~m}$.As shown in figure 1 and figure 2.

Table 1: Calculation of material parameters

\begin{tabular}{|c|c|c|c|}
\hline \multirow{2}{*}{ parameter } & \multirow{2}{*}{ unit } & \multicolumn{2}{|c|}{ material } \\
\cline { 3 - 4 } & & concrete & soil \\
\hline $\mathrm{E}$ & $\mathrm{Pa}$ & $3.15 \mathrm{E} 10$ & $10 \mathrm{E} 6$ \\
\hline $\mathrm{v}$ & & 0.3 & 0.3 \\
\hline$\gamma$ & $\mathrm{kN} \cdot \mathrm{m}-3$ & 25 & 16.8 \\
\hline$\phi$ & $\left(^{\circ}\right)$ & & 33.7 \\
\hline $\mathrm{c}$ & $\mathrm{kPa}$ & & 10 \\
\hline
\end{tabular}
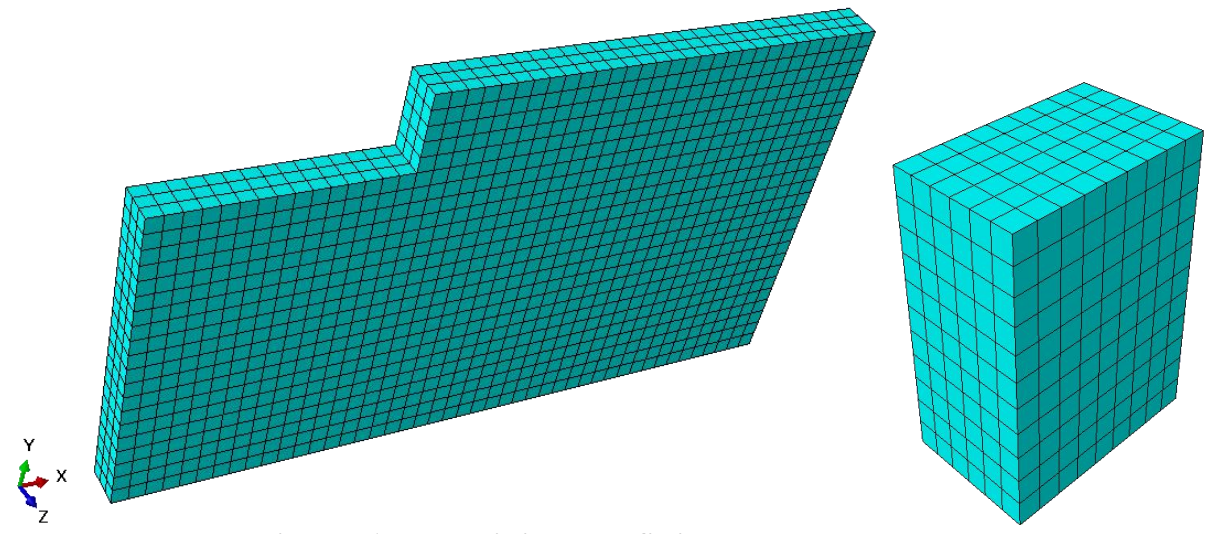

Figure 1: The rigid wall finite element meshes

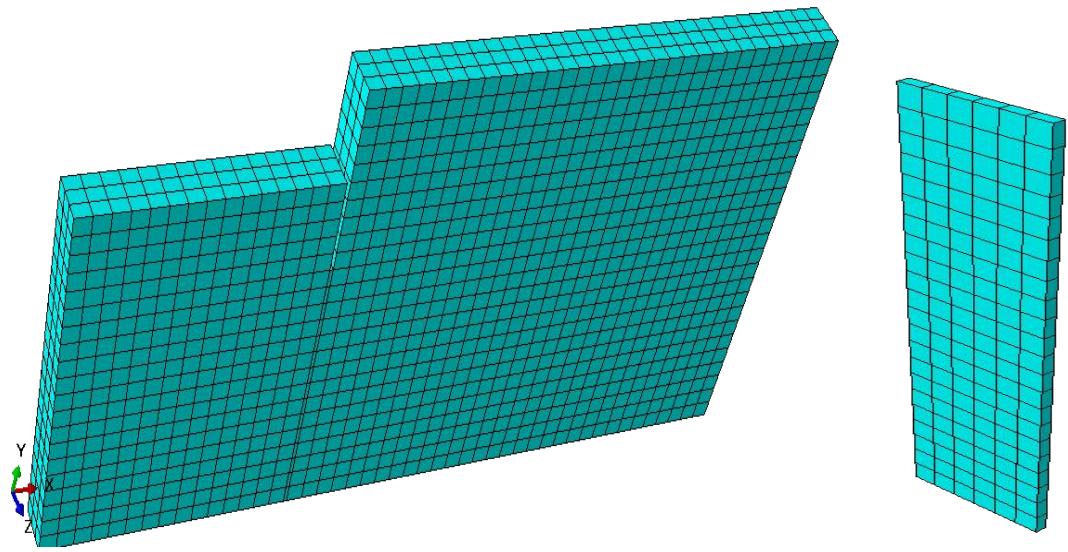

Figure 2: The flexible wall finite element meshes 
The stress analysis of retaining wall

The stress nephogram of the rigid retaining wall

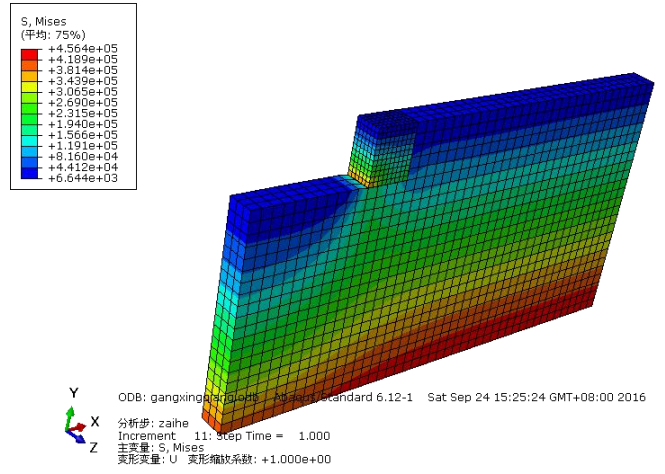

Figure 3: Total stress nephogram

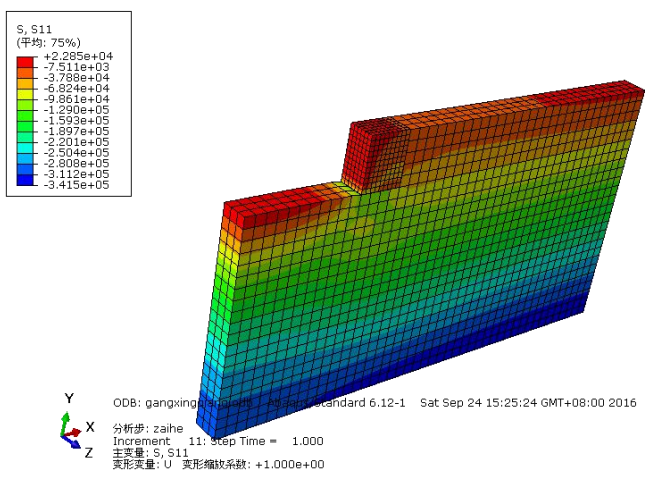

Figure 4: $X$ direction normal stress nephogram

The stress nephogram of the flexible retaining wall

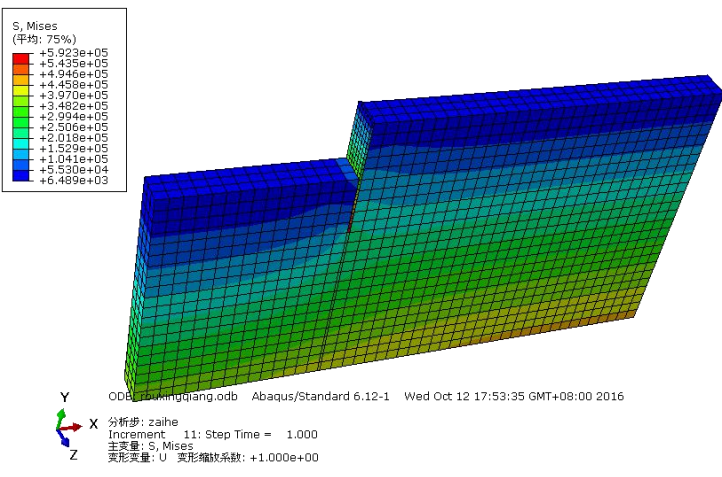

Figure 5: The total stress nephogram

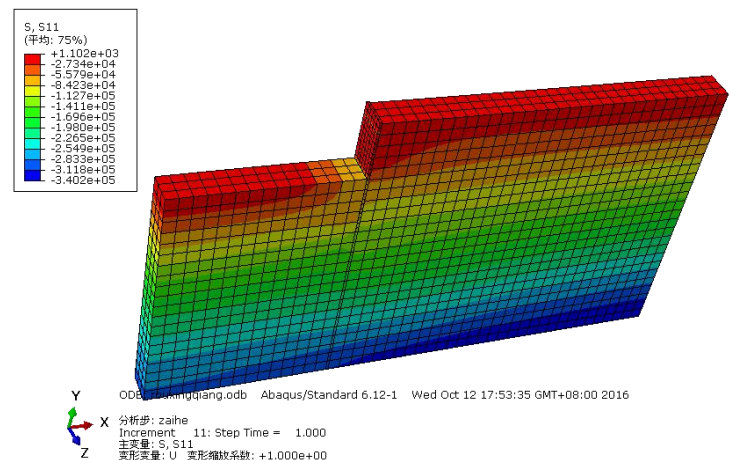

Figure 6: $\mathrm{X}$ direction normal stress nephogram

The earth pressure on rigid retaining wall of different cross section (units:KPa)

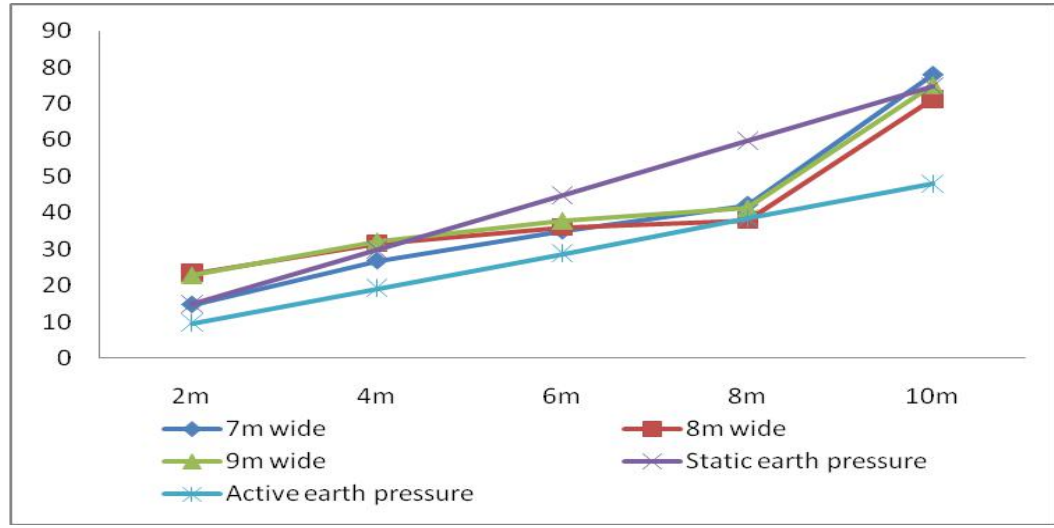

Figure 7: The earth pressure on rigid retaining wall of different cross section

The earth pressure on rigid retaining wall of different load pressure (units:KPa)

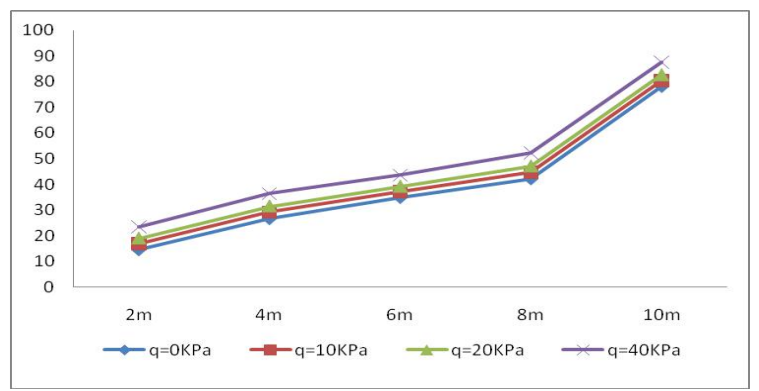

Figure 8: The earth pressure on rigid retaining wall of different load pressure

The earth pressure on flexible retaining wall of different load pressure (units:KPa) 


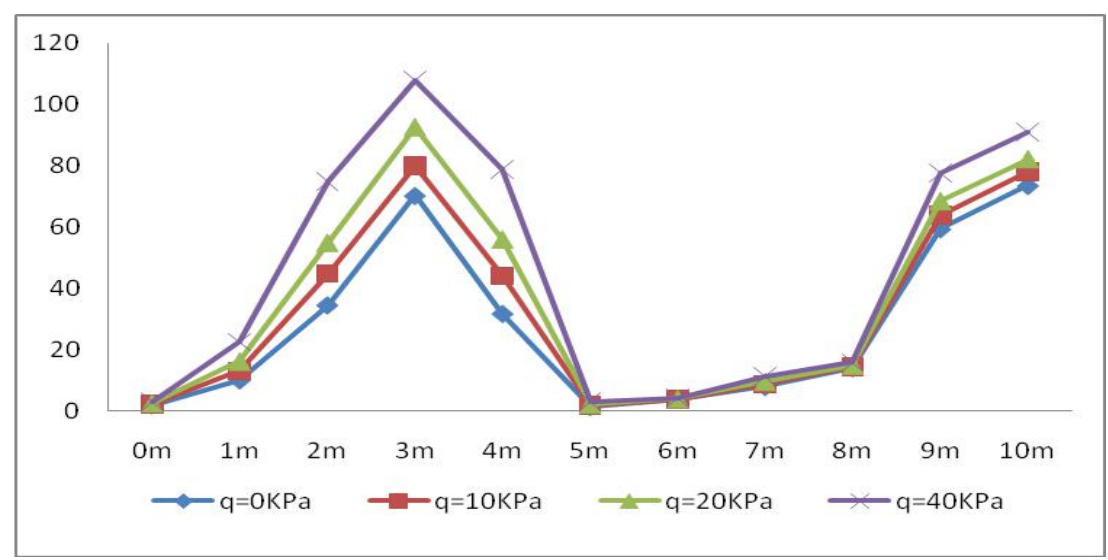

Figure 9: The earth pressure on flexible retaining wall of different load pressure

\section{The result analysis}

(1) According to the figure 7,it can be seen that the earth pressure is between the active earth pressure and the static earth pressure, and Curve similar to static earth pressure. When displacement is very small, it can be drawn that the earth pressure on the rigid wall Can be seen as the static earth pressure, and it can be seen that the displacement mode of gravity retaining wall is RB mode, moreover, the numerical results obtained by the bottom of the wall near the earth pressure value is significantly higher than the value of the static earth pressure, Fang (1986), Matsuzawa (1996) named the "dead zone" which is the soil area of earth pressure near the bottom of the wall keeping high value, this model better simulate the "dead zone". The influence of the earth pressure on the Retaining wall which due to the change of retaining wall' stiffness can be thought of as the change of the transition between the active earth pressure to the static earth pressure ${ }^{[4]}$.

(2) According to the figure 8, you can see the earth pressure on the Retaining wall become a linear change under the distribution of the average load. The change of the load redistribution the earth pressure on the Retaining wall, the pressure value is proportional to the increase from wall to wall.

(3) According to the figure 9, it can be seen that the distribution of the earth pressure on the flexible retaining wall was $\mathrm{R}$ type distribution. The top of the sheet pile wall be constraints, the bottom is embedded in the foundation. The displacement of the upper and lower is smaller, while the displacement in the middle is larger. Wall of the soil arch occurs in the process of sheet pile wall deformation, part of the earth pressure in the middle spread up and down by the frictional force of the sliding soil. Under the distribution of the average load the change of the earth pressure value is more obvious $^{[5]}$.

(4) This numerical simulation, with using the ABAQUS finite element software to simulate, either rigid or flexible wall, both can be well simulated, and reflected the change of earth pressure can be very good under the load, so the finite element software ABAQUS geotechnical problem is feasible.

\section{References}

[1], Hai-hong Mo, Xiao-ping Yang. Basic engineering. China building industry press, 2008;

[2] Kang Fei. Jian-wei Zhang. Gui-jun Han. ABAQUS in geotechnical engineering, China Water Power Press (in Chinese). 2009.

[3] Yu-zhuo Wang, Chuan-guo Fu. ABAQUS structural engineering analysis and example explanation. China building industry press, 2010

[4] Matsuzawa,H.,and Hazarika,H.Analyses of active earth pressure against rigid retaining walls subjeeted to different modes of movement[J].Soils and Foundations, 1996;

[5] Li-an Han, Yu-yao Xi. Port hydraulic structures. People's traffic press, 2001 